in vivo $33: 1985-1992(2019)$

doi:10.21873/invivo.11694

\title{
Simultaneous Integrated Boost in Once-weekly Hypofractionated Radiotherapy for Breast Cancer in the Elderly: Preliminary Evidence
}

\author{
ELISABETTA BONZANO ${ }^{1 \#}$, LILIANA BELGIOIA $^{1}$, GIORGIA POLIZZI $^{1}$, GUIDO SIFFREDI $^{1}$, \\ PIERO FREGATTI ${ }^{2}$, DANIELE FRIEDMAN ${ }^{2}$, STEFANIA GARELLI $^{3}$, MARCO GUSINU $^{3}$, \\ ELENA MARIA LUISA VACCARA ${ }^{3}$, MARINA GUENZI $^{1 *}$ and RENZO CORVÒ ${ }^{1 *}$ \\ ${ }^{1}$ Department of Radiation Oncology, IRCCS Policlinico San Martino, Genoa, Italy; \\ ${ }^{2}$ Department of Surgery, IRCCS Policlinico San Martino, Genoa, Italy; \\ ${ }^{3}$ Department of Medical Physics, IRCCS Policlinico San Martino, Genoa, Italy
}

\begin{abstract}
Aim: To evaluate once-weekly hypofractionated radiotherapy in elderly patients affected by early breast cancer, reporting acute and late toxicity profiles, and treatment feasibility. Patients and Methods: Fifty patients were treated with a hypofractionated regimen: $28.5 \pm 2.5 \mathrm{~Gy}$ in five fractions at one fraction weekly. Simultaneous integrated boost (SIB) to the tumor bed in high-risk cases. Inclusion criteria: patients over 70 years old, pT1-2, NO-1a. Acute and late toxicities were assessed based on Radiation Therapy Oncology Group. Results: The median follow-up was 20 months and the median patient age was 79 years. SIB was added for 22 patients (44\%). Grade 3-4 acute cutaneous toxicities were not observed; grade 2 toxicity occurred only in four patients (8\%). Late subcutaneous tissue toxicity consisted of grade 2 fibrosis in two patients (4\%), grade 1 in five (10\%) and grade 0 in 41(85\%). Conclusion: Limiting fraction numbers with a safer profile may improve the management of breast cancer for the elderly.
\end{abstract}

Breast cancer is the most common type of cancer affecting females worldwide (1). About one-half of all newly

This article is freely accessible online.

*These Authors contributed equally to this study.

\#Currently at: Department of Radiation Oncology, Fondazione IRCCS Policlinico San Matteo, Pavia, Italy, and Ph.D. in Experimental Medicine, Faculty of Medicine, University of Pavia, Pavia, Italy.

Correspondence to: Elisabetta Bonzano, Viale Camillo Golgi 19, 27100, Pavia, Italy. Tel: +39 3381976745, e-mail: elisabettabonzano@ gmail.com

Key Words: Radiotherapy, elderly, hypofractionation, breast cancer. diagnosed breast cancer cases occur in women older than 65 years (2). Several randomized clinical trials and metaanalyses have demonstrated that adjuvant radiotherapy plays a fundamental role in reducing the risk of tumor recurrence and improving survival (3). The standard recommended radiation dose is $50 \mathrm{~Gy}$ in 25 fractions of $2 \mathrm{~Gy}$, five times per weeks, with a boost of 10 to 16 Gy to the tumor bed (4). This fractionation of radiation dose lasts 6 weeks and may be challenging in the elderly.

Nowadays, the use of hypofractionated schemes has become increasingly common, achieving a shorter treatment course, lower treatment costs, and shorter radiation therapy waiting times (4-6). Several trials in the literature demonstrated the efficacy and safe of hypofractionated radiation therapy $(7,8)$. The START A and B trials $(9,10)$ and the Canadian Trial (4) showed comparable results between the hypofractionated schemes and the conventional one. Finally, the UK FAST trial, a randomized trial, compared two different regimens of hypofractionated radiotherapy $(28.5 \mathrm{~Gy}$ in five fractions and $30 \mathrm{~Gy}$ in five fractions over 5 weeks) versus conventional radiotherapy, showing comparable outcomes (7).

In studies of elderly patients diagnosed with breast cancer, the impact of aging and the increased likelihood of concomitant comorbidity should be taken into account (11). The omission of postoperative radiotherapy in the elderly is still a matter of debate (12).

In a comprehensive cohort study about patient compliance with adjuvant standard breast radiation treatment, Harun et al. found significant correlation between noncompliance and unceasing patient age $(p<0.0005)$ may be due to comorbidities and low radiotherapy tolerance of elderly patients. This evidence suggests that an improvement is needed because the omission of radiation treatment results in a higher local failure rate, and means a worse clinical outcome (13). 
Table I. Radiation Therapy Oncology Group classification of skin and subcutaneous tissue toxicity after radiotherapy (22).

\begin{tabular}{|c|c|c|c|c|}
\hline & \multicolumn{4}{|c|}{ RTOG grade } \\
\hline & 1 & 2 & 3 & 4 \\
\hline Acute skin criteria & $\begin{array}{c}\text { Follicular, faint or dull erythema/ } \\
\text { epilation/dry desquamation/ } \\
\text { decreased sweating }\end{array}$ & $\begin{array}{l}\text { Tender or bright erythema, } \\
\text { patchy moist desquamation, } \\
\text { moderate edema }\end{array}$ & $\begin{array}{c}\text { Confluent, moist desquamation } \\
\text { other than skin folds, } \\
\text { pitting edema }\end{array}$ & $\begin{array}{l}\text { Ulceration, } \\
\text { hemorrhage, } \\
\text { necrosis }\end{array}$ \\
\hline Late skin criteria & $\begin{array}{l}\text { Slight atrophy; pigmentation } \\
\text { change; some hair loss }\end{array}$ & $\begin{array}{l}\text { Patch atrophy; moderate } \\
\text { telangiectasia; total hair loss }\end{array}$ & $\begin{array}{l}\text { Marked atrophy; } \\
\text { gross telangiectasia }\end{array}$ & Ulceration \\
\hline $\begin{array}{l}\text { Late subcutaneous } \\
\text { tissue criteria }\end{array}$ & $\begin{array}{l}\text { Slight induration (fibrosis) } \\
\text { and loss of subcutaneous fat }\end{array}$ & $\begin{array}{l}\text { Moderate fibrosis but } \\
\text { asymptomatic; slight field } \\
\text { contracture; }<10 \% \\
\text { linear reduction }\end{array}$ & $\begin{array}{l}\text { Severe induration and } \\
\text { loss of subcutaneous } \\
\text { tissue; field contracture } \\
>10 \% \text { linear measurement }\end{array}$ & Necrosis \\
\hline
\end{tabular}

Several studies investigated the effect of omission of whole-breast radiotherapy in elderly women to assess the impact on local control and low risk of local recurrence at 5 years $(14,15)$. Indeed, there is an increasing interest in identifying a subgroup of patients with favorable prognostic factors (node-negative, hormone-sensitive, low-grade, negative surgical margins) for whom radiation therapy may be avoided without compromising outcomes $(14,16,17)$. According to Kunkler et al., there is still no subgroup of elderly in whom adjuvant radiotherapy can be systematically omitted after breast-conserving surgery, and shortened (hypofractionated) dose fraction schedules may be more convenient for older patients, as supported by level 1 evidence (17). A short fractionation schedule, in fact, appears promising to ensure control of residual cancer cells after surgery in elderly women, who may have hindrances attending hospital several times.

Here we report our experience by testing this 'innovative' fractionation approach in clinical practice. An intensification of radiation dose was also planned in selected women at high risk of recurrence. This was a retrospective monoinstitutional study, the endpoint of which was to evaluate the treatment feasibility and safety, concerning acute and subacute skin toxicity, late tissue toxicity and clinical outcomes. It is the first report of the use of a once-weekly hypofractionated schedule with the addition of a simultaneous integrated boost (SIB); to our knowledge, no similar once-weekly regimen has been published, all the previous studies which included the addition of a boost analyzed the use of a sequential one.

\section{Patients and Methods}

Only patients with tumor $<\mathrm{pT} 2$ and $<\mathrm{pN} 1 \mathrm{a}$, aged over 70 years (median age 79 years, range $=72-90$ years), with no severe comorbidities, such as high-severity heart disease, cardiac arrest, congestive heart failure, chronic obstructive pulmonary disease, and with performance status (PS) 0-2, and no cognitive impairment, were enrolled in this study. All the patients gave their written informed consent to participation and use of data.

A hypo-fractionation regimen was prescribed of $28.5 \mathrm{~Gy}$ in five fractions, one fraction weekly, plus an intensification of radiation dose by SIB. The SIB consisted of the delivery of 2.5 Gy $(0.5 \mathrm{~Gy}$ each fraction) to the tumor bed, in high-risk cases $(22 / 50,44 \%)$, according to high grading (G3), positive margins, and unfavorable biological pattern (hormone-receptor-negative, triple-negative or human epidermal growth factor receptor 2 (HER2)-positive disease, Ki-67 $\geq 20 \%$ ).

Planning parameters and treatment techniques. A planning computed tomographic (CT) scan was scheduled for each patient. Patients were positioned on a wing-board with both arms raised above the head. All CT scans were performed from the level of the larynx to the level of the upper abdomen, including both lungs, with a scan thickness and index of $5 \mathrm{~mm}$. A radiopaque wire was placed encompassing the breast circumferentially for clinical reference. Furthermore, four tattoos were marked in the supine position (two on the sternal midline and one on each axillary midline) to ensure the reproducibility of the setup (18).

The CT data were transmitted to an Eclipse Treatment Planning System (Varian, Palo Alto, CA, USA). The clinical target volume (CTV) included all the glandular breast tissue of the ipsilateral breast and, where prescribed to the lumpectomy cavity, the SIB, guided by the presence of surgical clips, as well as by hematoma, seroma or other surgery-induced changes. The planning target volume (PTV) consisted of $5 \mathrm{~mm}$ expansion of the CTV in all directions except the skin. The structures outlined (organs at risk, OARs) included the heart, the left anterior descending coronary artery (LADCA), and ipsilateral lung (18).

The treatment was delivered in the supine position, with step-andshoot 3D-conformal radiation therapy. For whole-breast irradiation, tangential field 3D-conformal radiation therapy was sufficient to obtain qualitative dosimetry. The dose was prescribed to the PTV.

Previous experience, for example, the START trial (9), considered use of a breast cancer $\alpha / \beta$ ratio lower than the traditional value for tumor cells of $10 \mathrm{~Gy}$, but similar to that of experimental evidence with a value between 4.0 and $4.6 \mathrm{~Gy}$, for the sensitivity of breast cancer to fractionation in the adjuvant setting $(19,20)$. According to the linear-quadratic model (19), we used the following schedule [the 
Table II. Study patient characteristics.

\begin{tabular}{|c|c|}
\hline Characteristic & Value \\
\hline \multicolumn{2}{|l|}{ Age, years } \\
\hline Median (range) & $79(72-90)$ \\
\hline$\leq 80$ Years, $\mathrm{n}(\%)$ & $26 / 50(56 \%)$ \\
\hline$>80$ Years, $\mathrm{n}(\%)$ & $22 / 50(44 \%)$ \\
\hline \multicolumn{2}{|c|}{ Histology (ductal carcinoma), n (\%) } \\
\hline Invasive & $48 / 50(96 \%)$ \\
\hline In situ & $2 / 50(4 \%)$ \\
\hline \multicolumn{2}{|l|}{ Pathological tumor stage, n (\%) } \\
\hline pTis-pT1 & $43 / 50(86 \%)$ \\
\hline pT2 & $7 / 50(14 \%)$ \\
\hline \multicolumn{2}{|l|}{ Tumor size } \\
\hline Median (range), $\mathrm{cm}$ & $1.25(0.5-3.5)$ \\
\hline \multicolumn{2}{|l|}{ Pathological nodal stage, n (\%) } \\
\hline pNO & $45 / 50(90 \%)$ \\
\hline $\mathrm{pN} 1 \mathrm{a}$ & $5 / 50(10 \%)$ \\
\hline \multicolumn{2}{|l|}{ Grading, n (\%) } \\
\hline G1 & $7 / 50(14 \%)$ \\
\hline G2 & $38 / 50(76 \%)$ \\
\hline G3 & $5 / 50(10 \%)$ \\
\hline \multicolumn{2}{|l|}{ Biology, n (\%) } \\
\hline Luminal A & $41 / 50(82 \%)$ \\
\hline Luminal B & $2 / 50(4 \%)$ \\
\hline HER2+ & $2 / 50(4 \%)$ \\
\hline Triple-negative & $3 / 50(6 \%)$ \\
\hline pTis & $2 / 50(4 \%)$ \\
\hline \multicolumn{2}{|c|}{ Hormone therapy (luminal A/B), n (\%) } \\
\hline Aromatase inhibitor & $41 / 43(95 \%)^{*}$ \\
\hline Tamoxifen & $2 / 43(5 \%)$ \\
\hline \multicolumn{2}{|l|}{ Breast size, $\mathrm{n}(\%)$} \\
\hline Median volume (range), $\mathrm{cm}^{3}$ & $553.95(195.6-1001.1)$ \\
\hline $1^{\circ}-3^{\circ}, \mathrm{n}(\%)$ & $23 / 50(46 \%)$ \\
\hline $4^{\circ}-7^{\circ}, \mathrm{n}(\%)$ & $27 / 50(54 \%)$ \\
\hline \multicolumn{2}{|l|}{ Laterality, n (\%) } \\
\hline Left & $30 / 50(60 \%)$ \\
\hline Right & $20 / 50(40 \%)$ \\
\hline
\end{tabular}

HER2: Human epidermal growth factor receptor 2. *One refusal.

$\alpha / \beta$ ratio of the START Trial (9)]: biologically effective dose $(\mathrm{BED})=n d(1+\mathrm{d} / \alpha / \beta)=5 \times 5.7(1+5.7 / 4.6)=28.5 \times 2.24=63.84 \mathrm{~Gy}$, where $n$ was the number of treatment fractions, and $d$ was the dose per fraction in Gy. For the SIB volume (when applicable), the dose was calculated as: $\mathrm{BED}=5 \times 6.2(1+6.2 / 4.6)=31 \times 2.35=72.7 \mathrm{~Gy}$, which provided a strong and acceptable adjuvant biological dosage. Because of this relationship, if the estimated $\alpha / \beta$ value decreases, the BED value increases. For the OARs of the left side (heart and LADCA), doses were calculated considering values of $\alpha / \beta$ for the heart of $2.5 \mathrm{~Gy}$ and for the LADCA of $1.7 \mathrm{~Gy}$. Regarding OARs, according to Nielsen et al. heart V $20<10 \%$, lung V $20<25 \%$ and V20 of 0 for LADCA are constraints to be respected (21). V20 was translated to V12 for radiobiological calculation, considering the hypofractionated schedule. The field-in-field technique was used to increase dose distribution homogeneity. Contralateral breast doses were kept as low as possible, but in cases of conflict between heart/lung dose versus contralateral breast, the heart dosage was given priority for these elderly patients.
Table III. Dosimetric results.

\begin{tabular}{|c|c|}
\hline Parameter & Result \\
\hline \multicolumn{2}{|l|}{ Breast coverage } \\
\hline$\geq 95 \%$ & Satisfied for all plans \\
\hline \multicolumn{2}{|l|}{ SIB coverage } \\
\hline$\geq 95 \%$ & Satisfied for all plans \\
\hline \multicolumn{2}{|l|}{ Breast PTV volume } \\
\hline Median (range), $\mathrm{cm}^{3}$ & $553.95(195.6-1001.1)$ \\
\hline \multicolumn{2}{|l|}{ SIB volume } \\
\hline Median (range), $\mathrm{cm}^{3}$ & $52.95(20.8-149.4)$ \\
\hline \multicolumn{2}{|l|}{ Heart (left side) } \\
\hline Median $\mathrm{D}_{\max }$ (range), Gy & $14.60(3.8-26.1)$ \\
\hline Median $\mathrm{D}_{\text {mean }}$ (range), Gy & $0.8(0.2-2.2$ \\
\hline \multicolumn{2}{|l|}{ LADCA (left side) } \\
\hline Median $\mathrm{D}_{\max }$ (range), Gy & $11.45(3.8-17.2)$ \\
\hline Median $\mathrm{D}_{\text {mean }}$ (range), Gy & $2.65(1.4-7.8)$ \\
\hline \multicolumn{2}{|l|}{ Lung } \\
\hline Median $\mathrm{D}_{\max }$ (range), Gy & $28.65(25.6-32.1)$ \\
\hline Median $\mathrm{D}_{\text {mean }}$ (range), Gy & $3.15(1.1-8.5)$ \\
\hline
\end{tabular}

SIB: Simultaneous integrated boost; LADCA: left anterior descending coronary artery; PTV: planning target volume; $\mathrm{D}_{\max }$ : maximum dose; $\mathrm{D}_{\text {mean }}$ : mean dose.

Radiation treatment was delivered over 5 weeks, once weekly. Each 5.7 Gy fraction plus SIB in high-risk patients was preceded by verification of radiological positioning.

Acute and late toxicity assessment. The primary endpoints of this analysis were acute skin toxicity and late skin and subcutaneous tissue toxicity, and clinical outcomes (remarkable changes in breasts appearance). Side-effects were evaluated according to Radiation Therapy Oncology Group (RTOG) scale (Table I) (22); desquamation was scored as none, dry, or moist. Edema, pain, pruritus, and fatigue were also registered. These features were assessed before radiotherapy, during each fraction, at the end of radiotherapy, and at 2 and 4 weeks after treatment. Long-term follow-up in the Radiation Therapy Department was limited to 6 months in the first year and every 12 months thereafter, to limit the additional burden of consultations for this specific patient group.

Chi-squared test was used to indicate the independence of toxicity from other variables (especially the SIB dosage) with a significance level of $p=0.05$.

\section{Results}

Clinical results. Between October 2016 and June 2017, 50 female patients with breast cancer were evaluated as being eligible for adjuvant hypo-fractionated radiotherapy, according to clinical characteristics $(<\mathrm{pT} 2$ and $<\mathrm{pN} 1 \mathrm{a}$, age over 70 years), patient willingness and performance status. Among 50 women selected, treatment was administered to 48; one patient died from thoracic aortic aneurysm fissure, before beginning radiotherapy (no cancer- nor treatmentrelated death); radiotherapy was interrupted for another 


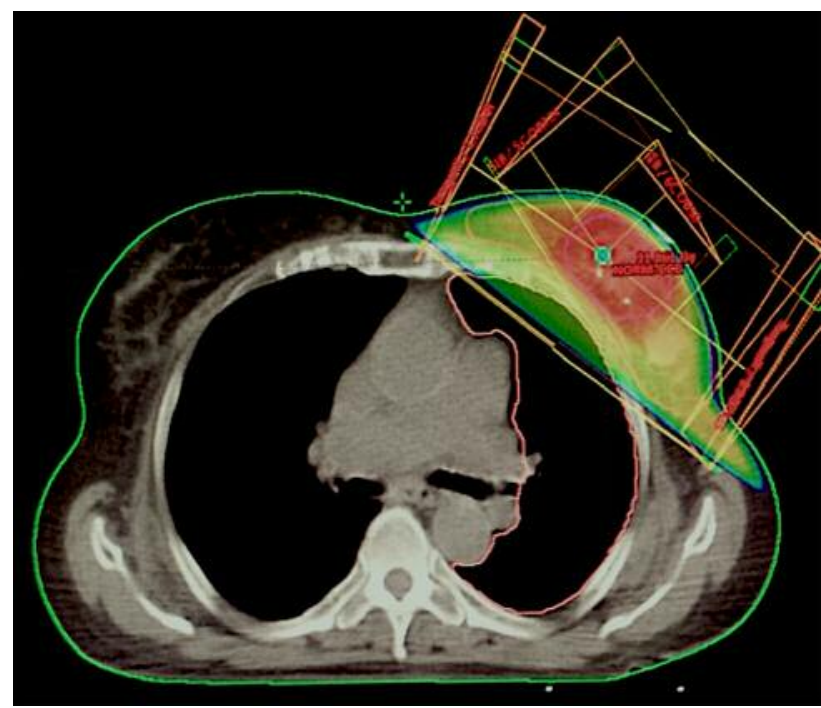

Figure 1. Example of simultaneous integrated boost dose distribution in irradiation of the left breast.

patient after three fractions at the patient's request, against physicians' advice.

The median follow-up time was 20 months and the median overall treatment time was 27 days (range $=26-43$ days).

Clinical characteristics analyzed were tumor stage (T1-2), nodal status (N0 -1a), grading (G1-3), HER2 expression (two patients HER2 $3+$ ), proliferative index (33 patients Ki-67 $<20 \%$ vs. 15 patients $\mathrm{Ki}-67>20 \%$ ), histological type [invasive ductal carcinoma 48/50 (96\%), and ductal carcinoma in situ: 2/50 (4\%)], hormonal status, and systemic therapy, laterality and size (overall medium). As regards nodal involvement, five patients had positive sentinel lymph nodes, two of them had only one micrometastasis, and the other three patients underwent nodal dissections, which were negative in all cases. According to immunohistochemistry data, patients' nodenegative, hormone receptor-positive, low Ki-67 value and negative HER2, 43 patients underwent adjuvant hormonal therapy; only one patient (2\%) also underwent adjuvant chemotherapy (taxol once weekly for 12 weeks); the remaining ones did not have systemic therapy due to their age (Table II).

To date, all treated patients are alive and free of local recurrence.

Dosimetric results. Good agreement with planning dosimetry constraints was found, with constraints to thoracic OARs (heart, LADCA, ipsilateral lung) according to Nielsen et al. (21) being respected. For left-sided cases, the median maximum $\left(\mathrm{D}_{\max }\right)$ and median mean $\left(\mathrm{D}_{\text {mean }}\right)$ doses were 14.6 and $0.8 \mathrm{~Gy}$ to the heart, 11.45 and $2.65 \mathrm{~Gy}$ to the LADCA, and 28.65 and $3.15 \mathrm{~Gy}$ to both sides of the lung, respectively, as reported in Table III.

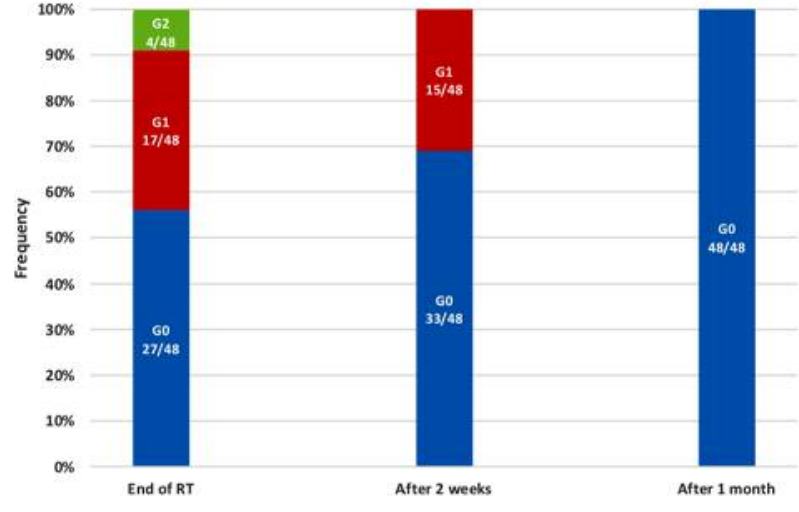

Figure 2. Acute skin toxicity experienced by study patients graded according to Radiation Therapy Oncology Group Scale (see Table I). RT: Radiotherapy.

For the LADCA, we obtained "translation" of conventional fractionation constraint (V20) with radiobiological calculation as V12 and this was 0 for all patients, except one due to anatomical conformity, for whom LADCA Dmax was 17.2, but we consider that this still respected the conventional fraction constraint (V20=0).

SIB technique (Figure 1) was used in 22/50 (44\%) cases and consisted of $0.5 \mathrm{~Gy}$ administered simultaneously to the tumor bed in addition to the PTV dose, at each fraction. The SIB volume was another CTV, and the sum-plan was considered acceptable with V12 LADCA of 0 . A criterion of 95\% coverage of the breast PTV and SIB PTV receiving the $95 \%$ of the prescribed dose was satisfied for all plans. The median breast volume was $553.95 \mathrm{~cm}^{3}$, and median SIB volume was $52.95 \mathrm{~cm} 3$ (Table III).

Acute skin toxicity. Patients were visited during weekly radiotherapy, at the end of treatment and subsequently and evaluated according to RTOG scale (22). Clinically relevant dermatitis and moist desquamation were uncommon; grade 3 and 4 dermatitis were not observed. At the end of radiotherapy, $4 / 48(8 \%)$ patients showed grade 2 toxicity and were successfully treated with topical steroid in the subsequent $2-3$ weeks; $17 / 48(35 \%)$ patients had grade 1 erythema; $27 / 48(56 \%)$ women had no clinical side-effects. Of these, 2 weeks after radiotherapy only 15 patients $(31 \%)$ manifested residual grade 1 toxicity and none after 1 month, as illustrated in Figure 2.

To investigate the potential correlation between acute toxicity and SIB administration, we performed a Chi-squared test, and it demonstrated the independence of these variables $(p=0.05)$.

Furthermore, in addition to minimal acute toxicity, clinical outcomes were encouraging: 40/48 patients (83\%) had good 
Table IV. Weekly hypofractionated schedules for breast cancer reported in literature.

\begin{tabular}{|c|c|c|}
\hline Author (Ref) & $\mathrm{N}$ & Radiation therapy schedule \\
\hline Agrawal et al., 2011 (32) & 915 & 50 Gy $(2 \mathrm{~Gy} \times 25)$ versus $28.5 \mathrm{~Gy}(5.7 \times 5)$ or $30 \mathrm{~Gy}(6 \mathrm{~Gy} \times 5)$ \\
\hline Rovea et al., 2015 (27) & 298 & 30 Gy $(6 \mathrm{~Gy} \times 5)$ or $32.5 \mathrm{~Gy}(6.5 \mathrm{~Gy} \times 5)$ \\
\hline Brunt et al., 2016 (33) & 352 & $\begin{array}{l}40 \mathrm{~Gy} \text { in } 15 \text { sessions in } 3 \text { weeks versus } 27 \text { Gy in } 5 \text { sessions } \\
\text { in } 1 \text { week or } 26 \text { Gy in } 5 \text { sessions in } 1 \text { week }\end{array}$ \\
\hline Dragun et al., 2017 (29) & 158 & $\begin{array}{l}30 \mathrm{~Gy}(6 \mathrm{~Gy} \times 5) \text { or } 28.5 \mathrm{~Gy}(5.7 \mathrm{~Gy} \times 5) \pm \text { boost } \\
10 \mathrm{~Gy} \text { in } 5 \text { sessions or } 8.1 \mathrm{~Gy} \text { in } 3 \text { sessions or } 5.7-6 \mathrm{~Gy} \text { in } 1 \text { session }\end{array}$ \\
\hline Ortholan et al., 2005 (31) & 150 & $6.5 \mathrm{~Gy} \times 5 ; 5.5 \mathrm{~Gy} \times 5 ; \pm$ boost $6.5 \mathrm{~Gy} \times 1$ or 2 \\
\hline Kirova et al., 2009 (30) & 367 & 32.5 Gy $(6.5 \mathrm{~Gy} \times 5)$ versus $50 \mathrm{~Gy}(2 \mathrm{~Gy} \times 25)$ \\
\hline Present study with dose intensification & 50 & $28.5(5.7 \mathrm{~Gy} \times 5) \pm \operatorname{SIB} 0.5 \mathrm{~Gy}$ \\
\hline
\end{tabular}

SIB: Simultaneous integrated boost.

clinical and cosmetic results, with no remarkable change in breast appearance, while $7 / 48(15 \%)$ and $1 / 48(2 \%)$ had acceptable and poor cosmetic outcomes, respectively.

Cutaneous acute toxicity was equally distributed on both breast sides and did not correlate with laterality or quadrant (by chi-squared test), with toxicity (G1 and G2 combined) at the end of radiotherapy in $36 \%$ of left-sided cases, and $50 \%$ of right-sided. Furthermore, the 20-month follow-up showed the once-weekly regimen to be a feasible treatment with a very low late toxicity rate and good clinical outcomes.

Late skin and subcutaneous tissue toxicity. Subcutaneous tissue toxicity was evaluated 20 months after treatment. The most common adverse event consisted in induration of the breast, defined as hardening of the tissue, and was used to assess fibrosis grade. Fibrosis grade 2 occurred only in two patients $(4 \%)$, grade 1 in five women $(10 \%)$ and most of the patients, 41(85\%), had no late event. Furthermore, regarding late skin toxicity, only one patient $(2 \%)$ developed grade 1 hyperpigmentation, limited to the surgical scar area. Esthetic outcomes were good to excellent in $94 \%$ and fair to poor in $6 \%$. At the last follow-up, all patients were satisfied by this short-course radiation regimen according to the low incidence of adverse events and good outcomes.

\section{Discussion}

Undertreatment in the elderly affects local control and diseasefree survival, especially in the intermediate- and high-risk groups (23). Hancke et al. reported that standard radiotherapy of female patients with breast cancer decreases substantially for women aged 70 years and older; in particular, women of this age often undergo recommended breast-conserving therapy ( $70-79$ years: $74 \%-83 \%$; $>79$ years: $54 \%)(24)$. It is well known that omission of adjuvant radiotherapy is related to a higher risk of local recurrence. Therefore, it is important to offer such treatment to all patients after breast-conserving surgery, including the elderly $(13,25)$.
A shorter schedule may reduce the inconvenience associated with numerous visits to the hospital and improve the quality of life (26), particularly important for the elderly given their difficulties in mobility, transportation, and even in financial turns. Moreover, such a schedule results in globally reducing treatment costs (27).

However, the feasibility and safety of accelerated treatment needs validation before becoming the new gold standard for early breast cancer care (28). Indeed, this analysis was reserved for testing hypofractionation only for women aged $>70$ years for whole-breast irradiation and SIB technique for the high-risk group.

In 2017, Dragun et al. published a phase II trial of onceweekly hypofractionated breast irradiation for 158 patients with early breast cancer ( 28.5 or $30 \mathrm{~Gy} /$ five weekly fractions + boost), leading to good cosmetic results and with a median follow-up 3 years (29).

Kirova et al. retrospectively compared an accelerated weekly schedule (32.5 Gy/6.5 Gy) with normo-fractionation in elderly patients and reported reassuring locoregional control and cause-specific survival. Groups were not equally balanced for age, performance status, tumor size, or presence of lymph node dissection, disfavoring the accelerated schedule. Lymph node irradiation and boost were limited to the normo-fractionation group. However, this schedule was an acceptable alternative to conventional treatment for elderly patients. The 5- and 7-year local recurrence-free survival rate was similar for the two groups: $95 \%$ and $93 \%$ for the normo-fractionation group and $94 \%$ and $91 \%$ for the one-weekly group (30).

A retrospective analysis of acceleration to five fractions in patients aged 80 (57-89) years by Rovea et al. (27) (32.5 Gy/6.5 Gy or 30 Gy/6 Gy weekly) showed no toxicity in $71.8 \%$ and grade 1 in $22.6 \%$ of patients, with only $6.1 \%$ clinically relevant dermatitis, as in our analysis.

In 2005, Ortholan et al. reported on a weekly hypofractionated schedule with a total dose of $32.5 \mathrm{~Gy}$ in five fractions, once a week. Data for 150 patients aged $>70$ 
years who underwent conservative breast surgery $(71.5 \%)$ and mastectomy $(28.5 \%)$, were analyzed. In $73.5 \%$ of patients, no dermatitis was observed, and in the remainder, it was limited to grade 1 and 2 in $18.6 \%$ and $9.4 \%$, respectively. This scheme resulted in mild early and late toxicity and provide excellent local control (31).

The 2011 FAST trial, a phase III randomized clinical trial of 915 patients with accrual between 2007 and 2011, compared 50 Gy in 25 fractions (control group) versus 28.5 Gy or 30 Gy in five fractions, once weekly. The study showed low rates of acute and late skin toxicity, concluding that once-weekly hypofractionation (with a dose of 28.5 Gy) was feasible and safe. The 28.5 Gy schedule was the same we used in our analysis, but in the FAST trial, no boost dose to the tumor bed was administered in any regimen. In our study, we adopted an intensified dose for patients at high risk of recurrence by delivering an SIB technique; this intensified dose did not appear to be correlated with any increase of acute or late toxicity (32). Other trials regarding late toxicity, cosmetic outcome, and, above all, rates of ipsilateral breast tumor recurrence have been undertaken or are ongoing [including FAST-Forward Trial (33)] in order to confirm that the 1-week, 5-fraction schedule is as effective and safe as the current regimen (Table IV).

Besides low incidence of acute and late toxicity, the onceweekly regimen increased treatment feasibility: among our patients, radiation therapy was discontinued for only one woman, and not for clinical reasons. Elderly patients often present other comorbidities that may limit frequent access to a hospital. In order to avoid poor adherence to adjuvant radiotherapy, once-weekly hypofractionation should be considered a valid treatment option.

This hypo-fractionated schedule is proven to be a feasible treatment, with minimal acute skin and late skin and subcutaneous tissue toxicity, comparable with published data on the other regimens. Moreover, dosimetric results were satisfying and in accordance with the literature. This regimen facilitates radiation treatment for elderly patients, who may rarely attend hospital, by limiting the number of fractions required and making this regimen safe.

\section{Conflicts of Interest}

There is no conflict of interest to disclose in regard to this study.

\section{Authors' Contributions}

EB: Wrote the article and reviewed final article. EB and GP: Performed data collection. SG, MG, ELV: Reviewed and edited final article and provided insight into how results relate to medical physics. GS: Performed data analysis and ran all statistical tests. LB MG and RC: Reviewed and edited final article and provided insight into how results relate to radiation oncology. DF and PF: Reviewed and edited final article and provided insight into how results relate to surgical oncology.

\section{References}

1 Shukla N, Hagenbuchner M, Win KT and Yang J: Breast cancer data analysis for survivability studies and prediction. Comput Methods Programs Biomed 155: 199-208, 2018. PMID: 29512500. DOI: 10.1016/j.cmpb.2017.12.011

2 Tesarova P: Breast cancer in the elderly - Should it be treated differently? Rep Pract Oncol Radiother 18: 26-33, 2012. PMID: 24381744. DOI: $10.1016 /$ j.rpor.2012.05.005

3 Smith BD, Bellon JR, Blitzblau R, Freedman G, Haffty B, Hahn C, Halberg F, Hoffman K, Horst K, Moran J, Patton C, Perlmutter J, Warren L, Whelan T, Wright JL and Jagsi R: Radiation therapy for the whole breast: Executive summary of an American Society for Radiation Oncology (ASTRO) evidence-based guideline. Pract Radiat Oncol 8: 145-152, 2018. PMID: 29545124. DOI: 10.1016/j.prro.2018.01.012

4 Whelan TJ, Pignol J-P, Levine MN, Julian JA, MacKenzie R, Parpia S, Shelley W, Grimard L, Bowen J, Lukka H, Perera F, Fyles A, Schneider K, Gulavita S and Freeman C: Long-term results of hypofractionated radiation therapy for breast cancer. N Engl J Med 362: 513-520, 2010. PMID: 20147717. DOI: 10.1056/NEJMoa0906260

5 Bellefqih S, Elmajjaoui S, Aarab J, Khalil J, Afif M, Lachgar A, El Kacemi H, Kebdani T and Benjaafar N: Hypofractionated regional nodal irradiation for women with node-positive breast cancer. Int J Radiat Oncol Biol Phys 97: 563-570, 2017. PMID: 28126305. DOI: 10.1016/j.ijrobp.2016.11.010

6 Guenzi M, Vagge S, Azinwi NC, D’Alonzo A, Belgioia L, Garelli S, Gusinu M and Corvò R: A biologically competitive 21 days hypofractionation scheme with weekly concomitant boost in breast cancer radiotherapy feasibility acute sub-acute and short term late effects. Radiat Oncol Lond 5: 111, 2010. PMID: 24377002. DOI: 10.1186/1748-717X-5-111PMID: 21092219

7 Kacprowska A and Jassem J: Hypofractionated radiotherapy for early breast cancer: Review of phase III studies. Rep Pract Oncol Radiother 17: 66-70, 2012. DOI: 10.1016/j.rpor.2011.10.003

8 Corvò R, Ricchetti F, Doino D, Torielli P, Agostinelli S, Cavagnetto F, Giannelli F, D'Alonzo A, Vagge S, Belgioia L and Guenzi M: Adjuvant hypofractionated radiotherapy with weekly concomitant boost for women with early breast cancer: the clinical experience at Genoa University. Anticancer Res 30: 4749-4753, 2010. PMID: 21115935.

9 START Trialists' Group, Bentzen SM, Agrawal RK, Aird EGA, Barrett JM, Barrett-Lee PJ, Bliss JM, Brown J, Dewar JA, Dobbs HJ, Haviland JS, Hoskin PJ, Hopwood P, Lawton PA, Magee BJ, Mills J, Morgan D a. L, Owen JR, Simmons S, Sumo G, Sydenham MA, Venables $\mathrm{K}$ and Yarnold JR: The UK Standardisation of Breast Radiotherapy (START) trial A of radiotherapy hypofractionation for treatment of early breast cancer: A randomised trial. Lancet Oncol 9: 331-341, 2008. PMID: 18356109. DOI: 10.1016/S1470-2045(08)70077-9

10 Haviland JS, Owen JR, Dewar JA, Agrawal RK, Barrett J, Barrett-Lee PJ, Dobbs HJ, Hopwood P, Lawton PA, Magee BJ, Mills J, Simmons S, Sydenham MA, Venables K, Bliss JM, Yarnold JR and START Trialists' Group: The UK Standardisation of Breast Radiotherapy (START) trials of 
radiotherapy hypofractionation for treatment of early breast cancer: 10-Year follow-up results of two randomised controlled trials. Lancet Oncol 14: 1086-1094, 2013. PMID: 24055415. DOI: $10.1016 / \mathrm{S} 1470-2045(13) 70386-3$

11 Yancik R, Wesley MN, Ries LA, Havlik RJ, Edwards BK and Yates JW: Effect of age and comorbidity in postmenopausal breast cancer patients aged 55 years and older. JAMA 285 : 885-892, 2001. PMID: 11180731. DOI: 10.1001/jama. 285.7.885

12 Giugliano FM, Falivene S, Esposito E, Di Franco R, Muto M, D'Aiuto $M$ and Muto P: External radiotherapy for breast cancer in the elderly. Aging Clin Exp Res 29: 149-157, 2017. PMID: 24403236. DOI: 10.1007/s40520-016-0655-x PMID: 27837457

13 Badakhshi H, Gruen A, Sehouli J, Budach V and Boehmer D: The impact of patient compliance with adjuvant radiotherapy: a comprehensive cohort study. Cancer Med 2: 712-717, 2013. DOI: $10.1002 / \mathrm{cam} 4.114$

14 Hughes KS, Schnaper LA, Bellon JR, Cirrincione CT, Berry DA, McCormick B, Muss HB, Smith BL, Hudis CA, Winer EP and Wood WC: Lumpectomy plus tamoxifen with or without irradiation in women age 70 years or older with early breast cancer: long-term follow-up of CALGB 9343. J Clin Oncol 31: 2382-2387, 2013. PMID: 23690420. DOI: $10.1200 / \mathrm{JCO}$ 2012.45.2615

15 Kunkler IH, Williams LJ, Jack WJL, Cameron DA and Dixon JM: Breast-conserving surgery with or without irradiation in women aged 65 years or older with early breast cancer (PRIME II): a randomised controlled trial. Lancet Oncol 16: 266-273, 2015. PMID: 25637340. DOI: 10.1016/S14702045(14)71221-5

16 Omitting Radiation in Older Breast Cancer Patients I Oncology CME. Available from: https://www.gotoper.com/publications/ ajho/2016/2016may/omitting-radiation-in-older-breast-cancerpatients (Last accessed July 23, 2019)

17 Kunkler I: Radiotherapy issues in elderly breast cancer patients. Breast Care 7: 453-459, 2012. PMID: 24715826. DOI: 10.1159/ 000345870

18 Guenzi M, Giannelli F, Bosetti D, Blandino G, Milanese ML, Pupillo F, Corvò R and Fozza A: Two different hypofractionated breast radiotherapy schedules for 113 patients with ductal carcinoma in situ: Preliminary results. Anticancer Res 33: 35033507, 2013. PMID: 23898126.

19 Astrahan M: Some implications of linear-quadratic-linear radiation dose-response with regard to hypofractionation. Med Phys 35: 4161-4172, 2008. PMID: 18841869. DOI: 10.1118/ 1.2969065

20 Kurtz JM: The clinical radiobiology of breast cancer radiotherapy. Radiother Oncol 75: 6-8, 2005. PMID: 15878094. DOI: $10.1016 /$ j.radonc.2005.03.017

21 Nielsen MH, Berg M, Pedersen AN, Andersen K, Glavicic V, Jakobsen EH, Jensen I, Josipovic M, Lorenzen EL, Nielsen HM, Stenbygaard L, Thomsen MS, Vallentin S, Zimmermann S, Offersen BV and Danish Breast Cancer Cooperative Group Radiotherapy Committee: Delineation of target volumes and organs at risk in adjuvant radiotherapy of early breast cancer: National guidelines and contouring atlas by the Danish Breast Cancer Cooperative Group. Acta Oncol 52: 703-710, 2013. PMID: 23421926. DOI: 10.3109/0284186X.2013.765064

22 Cox JD, Stetz J and Pajak TF: Toxicity criteria of the Radiation Therapy Oncology Group (RTOG) and the European Organization for Research and Treatment of Cancer (EORTC). Int J Radiat Oncol Biol Phys 31: 1341-1346, 1995. PMID: 23838924. DOI: 10.1016/0360-3016(95)00060-C

23 Weiss A, Noorbakhsh A, Noorbaksh A, Tokin C, Chang D and Blair SL: Hormone receptor-negative breast cancer: Undertreatment of patients over 80. Ann Surg Oncol 20: 32743278, 2013. DOI: 10.1245/s10434-013-3115-2

24 Hancke K, Denkinger MD, König J, Kurzeder C, Wöckel A, Herr D, Blettner M and Kreienberg R: Standard treatment of female patients with breast cancer decreases substantially for women aged 70 years and older: A German clinical cohort study. Ann Oncol 21: 748-753, 2010. PMID: 19825884. DOI: 10.1093/ annonc/mdp364

25 Rivin del Campo E and Rivera S: Radiothérapie hypofractionnée des cancers du sein chez la femme âgée: état des lieux et perspectives. Cancer/Radiothérapie 22: 635-639, 2018. PMID: 28602405. DOI: 10.1016/j.canrad.2018.07.127

26 Movsas B: Radiation therapy in elderly persons: An old issue with new approaches. Int J Radiat Oncol Biol Phys 98: 715-717, 2017. DOI: $10.1016 /$ j.ijrobp.2016.11.032

27 Rovea P, Fozza A, Franco P, De Colle C, Cannizzaro A, Di Dio A, De Monte F, Rosmino C, Filippi AR, Ragona R and Ricardi $\mathrm{U}$ : Once-weekly hypofractionated whole-breast radiotherapy after breast-conserving surgery in older patients: A potential alternative treatment schedule to daily 3-week hypofractionation. Clin Breast Cancer 15: 270-276, 2015. PMID: 25666079. DOI: 10.1016/j.clbc.2014.12.011

28 Early Breast Cancer Trialists' Collaborative Group (EBCTCG), Darby S, McGale P, Correa C, Taylor C, Arriagada R, Clarke M, Cutter D, Davies C, Ewertz M, Godwin J, Gray R, Pierce L, Whelan T, Wang Y and Peto R: Effect of radiotherapy after breast-conserving surgery on 10year recurrence and 15-year breast cancer death: meta-analysis of individual patient data for 10,801 women in 17 randomised trials. Lancet 378: 1707-1716, 2011. PMID: 22019144. DOI: 10.1016/S0140-6736(11)61629-2

29 Dragun AE, Ajkay NJ, Riley EC, Roberts TL, Pan J, Rai SN, Jain D, Quillo AR, Scoggins CR, McMasters KM and Woo SY: First results of a phase 2 trial of once-weekly hypofractionated breast irradiation (WHBI) for early-stage breast cancer. Int J Radiat Oncol Biol Phys 98: 595-602, 2017. PMID: 28581400. DOI: 10.1016/j.ijrobp.2017.01.212

30 Kirova YM, Campana F, Savignoni A, Laki F, Muresan M, Dendale R, Bollet MA, Salmon RJ, Fourquet A and Institut Curie Breast Cancer Study Group: Breast-conserving treatment in the elderly: Long-term results of adjuvant hypofractionated and normo-fractionated radiotherapy. Int J Radiat Oncol Biol Phys 75: 76-81, 2009. PMID: 19168297. DOI:10.1016/j.ijrobp. 2008.11.005

31 Ortholan C, Hannoun-Lévi J-M, Ferrero J-M, Largillier R and Courdi A: Long-term results of adjuvant hypofractionated radiotherapy for breast cancer in elderly patients. Int $\mathrm{J}$ Radiat Oncol Biol Phys 61: 154-162, 2005. PMID: 15629606. DOI: 10.1016/j.jirobp.2004.04.059

32 FAST Trialists group, Agrawal RK, Alhasso A, Barrett-Lee PJ, Bliss JM, Bliss P, Bloomfield D, Bowen J, Brunt AM, Donovan E, Emson M, Goodman A, Harnett A, Haviland JS, Kaggwa R, Morden JP, Robinson A, Simmons S, Stewart A, Sydenham MA, Syndikus I, Tremlett J, Tsang Y, Wheatley D, Venables $\mathrm{K}$ and Yarnold JR: First results of the randomised 
UK FAST Trial of radiotherapy hypofractionation for treatment of early breast cancer (CRUKE/04/015). Radiother Oncol J Eur Soc Ther Radiol Oncol 100: 93-100, 2011. PMID: 21752481. DOI: 10.1016/j.radonc.2011.06.026

33 Brunt AM, Wheatley D, Yarnold J, Somaiah N, Kelly S, Harnett A, Coles C, Goodman A, Bahl A, Churn M, Zotova R, Sydenham M, Griffin CL, Morden JP, Bliss JM and FASTForward Trial Management Group: Acute skin toxicity associated with a 1-week schedule of whole breast radiotherapy compared with a standard 3-week regimen delivered in the UK FAST-Forward Trial. Radiother Oncol 120: 114-118, 2016. PMID: 27046390. DOI: $10.1016 /$ j.radonc .2016 .02 .027
Received July 8, 2019

Revised July 23, 2019

Accepted July 30, 2019 